\title{
Effects of two different memory training approaches in very preterm- born children
}

\author{
Regula Everts ${ }^{1,2,3^{*}}$, Manuela Wapp ${ }^{1,2,3}$, Barbara C. Ritter ${ }^{1}$, Walter Perrig ${ }^{2,4}$, Maja Steinlin ${ }^{1,2}$ \\ 1 Division of Neuropediatrics, Development and Rehabilitation, Children's University Hospital, Inselspital, Bern, Switzerland 2 Center \\ for Cognition, Learning, and Memory, University of Bern, Bern, Switzerland 3 Institute of Diagnostic and Interventional Neuroradiology, \\ University Hospital, Inselspital, Bern, Switzerland 4 Institute of Psychology, University of Bern, Bern, Switzerland
}

\begin{abstract}
Background: Little research has been conducted to assess the effect of using memory training with schoolaged children who were born very preterm. This study aimed to determine whether two types of memory training approaches resulted in an improvement of trained functions and/or a generalization of the training effect to non-trained cognitive domains.
\end{abstract}

Methods: Sixty-eight children born very preterm (7-12 years) were randomly allocated to a group undertaking memory strategy training $(n=23)$, working memory training $(n=22)$, or a waiting control group $(n=23)$. Neuropsychological assessment was performed before and immediately after the training or waiting period, and at a six-month follow-up.

Results: In both training groups, significant improvement of different memory domains occurred immediately after training (near transfer). Improvement of non-trained arithmetic performance was observed after strategy training (far transfer). At a six-month follow-up assessment, children in both training groups demonstrated better working memory, and their parents rated their memory functions to be better than controls. Performance level before the training was negatively associated with the training gain.

Conclusions: These results highlight the importance of cognitive interventions, in particular the teaching of memory strategies, in very preterm-born children at early school age to strengthen cognitive performance and prevent problems at school.

Citation: Everts R, Wapp M, Ritter BC, Perrig W, Steinlin M (2015) Effects of two different memory training approaches in very preterm-born children. Adv Pediatr Res 2:13. doi:10.12715/apr.2015.2.13

Received: February 10, 2015; Accepted: April 23, 2015; Published: May 25, 2015

Copyright: (C) 2015 Everts et al. This is an open access article distributed under the terms of the Creative Commons Attribution License, which permits unrestricted use, distribution, and reproduction in any medium, provided the original work is properly cited.

Competing interests: The authors have declared that no competing interests exist.

Sources of funding: This research project was supported by the Swiss National Science Foundation (grant numbers PZ00P1_126309 and PZ00P1_143173).

*Email: regula.everts@insel.ch

\section{Introduction}

Children born very preterm $(<32$ weeks of gestation) and/or with very low birth weight $(<1500 \mathrm{~g})$ show increasing survival rates thanks to advances in neonatal care. However, even in healthy preterm-born children, reading, writing, arithmetic, and attention are more often impaired than in children born at full term [1]. Scholastic problems can be related to difficulties in learning and remembering information [2]. These observations highlight the need for a special memory-based training program to prevent school problems and strengthen cognitive performance in very preterm-born children.

Memory training research distinguishes between two different training approaches: restitution and substitution [3]. The restitution approach is based on the assumption that memory capacity can be 
increased through intensive practice, and is often carried out using working memory training [4]. The substitution approach implies the use of internal strategies, namely memory strategies (such as rehearsal or chaining $[5,6]$ ), in order to facilitate encoding, maintenance and recall of information. The aim of all memory training is to improve trained aspects of memory and structurally similar memory tasks (near transfer). In best case scenarios, memory training can also confer a generalization of the training effect to other non-trained, structurally different cognitive domains (far transfer).

Memory strategy training is often used in adult neurorehabilitation in order to enhance learning and the ability to remember after brain injury. However, it has been suggested that the use of memory strategies at early school age can also induce an improvement of verbal short-term memory, an increase in verbal learning [5], or amelioration of general knowledge and vocabulary [7]. Controversial study results exist as to whether memory strategy training induce a transfer effect. Some authors conclude that memory strategy training entails only a near transfer effect to structurally similar aspects of memory, and does not transfer to other memory domains or even cognitive domains unrelated to memory $[8,9]$. Others present evidence to suggest there is indeed a far transfer of memory strategy training: in healthy young adults, the imagination strategy [10], the chaining strategy [6] and the rehearsal strategy [5] led to improvements of working memory. Likewise, teaching a combination of the rehearsal and organization strategies to school-aged children after stroke revealed a far transfer effect with improvements in non-trained verbal learning [11]. Both a near and far transfer effect was observed in a study teaching ten different memory strategies to children with memory problems; immediately after receiving the training they showed improvements in short-term memory and visual learning, but also an amelioration of general knowledge and vocabulary [7]. However, none of these studies has examined the long-term effect of memory strategy training after a few months.

Working memory is an important precondition for the attainment of school-relevant functions such as reading [12], arithmetic [13], executive control, and problem solving [14], and is closely related to general intelligence [15]. In line with the close association of working memory with many higher order cognitive functions, working memory training studies claim improvement of working memory but also an improvement of non-trained functions such as fluid intelligence [16], reading performance [17, 18], arithmetic [19], attention [20] and executive functions $[4,21]$ in children and adults. Even three months after completion of working memory training, fluid intelligence is suggested to be increased [16], inferring that this type of training has a far transfer effect. However, just as for memory strategy training, the far transfer effect of working memory training is put into question; some studies have suggested that working memory training merely increases the trained function per se [19, 22].

The success of memory strategy training depends on certain influencing factors. Since age and experience help the child to choose the strategy that is most effective [23], the age range is central to training effect. Whether a child's intelligence has an influence on the training effect or not is unclear. Intelligent children might already apply memory strategies themselves before receiving memory strategy training and hence benefit less from this type of instruction. Additional factors such as motivation or number of training sessions are expected to influence the effect of memory training in children. The child's brain is in a process of rapid maturation and is therefore thought to possess particular plasticity, allowing for rapid learning within a short period of time. Thus, training effects in children are suggested to be stronger than in adults [24].

We hypothesize that, independent of the training approach, memory training activities lead to improvements in memory and non-trained functions (near and far transfer) in very preterm-born schoolaged children immediately after receiving the training and at a six-month follow-up.

We will test this hypothesis by using a randomized, controlled and blinded study design. Evidence of a training effect would open up new opportunities to strengthen cognitive performance and prevent scholastic problems in very preterm-born children, but also in school-aged children with learning problems of other etiologies. 


\section{Methods}

This study reports on a subset of data from the NEMO (NEuropsychology and meMOry) research project at the Children's University Hospital, Inselspital, Bern, Switzerland. The NEMO project examines cognitive development and traininginduced changes in school-aged very preterm-born children. The ethics committee of the Children's University Hospital, Inselspital (Ethikkommission der Kinderkliniken Bern) and the regional ethics committee (Kantonale Ethikkommission Bern) approved the study protocol. All children and caregivers provided informed written consent prior to participation, consistent with the Code of Ethics of the World Medical Association (Declaration of Helsinki).

\section{Participants}

Very preterm-born children $(<32$ weeks of gestational age) and/or children with very low birth weight $(<1500 \mathrm{~g})$ born in the 1998-2003 cohort at the Children's University Hospital Bern were assessed within the scope of the NEMO research program. Inclusion criteria were: aged between 7 and 12 years, no or mild neonatal cerebral lesions (maximum hemorrhage grade I), no or mild periventricular leukomalacia (maximum grade II), no chronic illness (e.g. birth deformities, congenital heart defects, cerebral palsy or epilepsy), no medical problems potentially influencing development (e.g. meningitis, encephalopathy or traumatic brain injury), no pervasive developmental disorders (e.g. autism), normal or corrected-to-normal vision and hearing, and IQ $>85$ as measured by neuropsychological assessment. The latter criterion of having an IQ $>85$ was chosen so that the study sample would represent the largest population of preterm-born children, namely those with an IQ within the normal range [25], and to avoid cognitive heterogeneity impacting on the ability to generalize results. Inclusion was determined by revising medical files and by evaluating the first neuropsychological assessment. A total of 76 children fulfilled the inclusion criteria and were invited to the Children's University Hospital via a mailshot, which included an information booklet for parents and one for children. A total of 68 very preterm or very low birth weight children agreed to participate in the study (35 boys, 33 girls; age mean, $M=9.56$ years, $S D=1.7$ ).

\section{Study design}

After a first neuropsychological assessment, a total of 68 children were randomly allocated to either the memory strategy training group $(n=23)$, the working memory training group $(n=22)$, or the control group $(n=23)$. Randomization was carried out as per the standard operating procedure of the Clinical Trial Unit, University of Bern (between-subject factor: group). Randomization and allocation was performed using sealed randomization envelopes (Envelock ${ }^{\circledR}$ Tamper Proof Evident Security Envelopes). The randomization process was stratified for age to achieve age-balanced groups.

Children underwent three neuropsychological assessments; time-point 1 (TP1) before the training or waiting control period; time-point 2 (TP2) immediately after training or waiting control period, and time-point 3 (TP3) six months after the training or waiting control period. Experienced clinical child neuropsychologists conducted all assessments; neuropsychologists blinded to the group allocation conducted assessment at TP2 and TP3. Mean time between TP1 and TP2 for the memory strategy training group was $M=70$ days (d), $S D=24$; for the working memory training group, $M=67 \mathrm{~d}, S D=18$; and for the control group, $M=64 \mathrm{~d}, S D=40$. Mean time between TP2 and TP3 for the memory strategy training group was $M=189 \mathrm{~d}, S D=20$; for the working memory training group, $M=185 \mathrm{~d}, S D=32$; and for the control group, $M=190 \mathrm{~d}, S D=30$.

\section{Training procedure}

Children randomly allocated to the memory strategy training group $(n=23)$ received four weekly 60minute 'Memo-Training' [26] sessions with a trained child neuropsychologist. These took place in a oneto-one setting at the Children's University Hospital. After each of the four training sessions, children practiced one of the memory strategies four times at home, resulting in an expected maximum of 16 homework sessions at 10 minutes per session. MemoTraining includes teaching and practicing of five 
different memory strategies in an adaptive manner. It trains encoding and recall strategies in the episodic and semantic memory domain and is not expected to directly affect working memory, short-term memory or everyday memory. The following memory strategies were taught: chaining (creating a story with items to be recalled), rehearsal (internal or external repetition of items to be recalled), similarities (a combination of items to be remembered with known ideas or cues), imagination or visualization (lively imagination of the items to be recalled), and symbolic coding (symbolic notes of items to be remembered). The training tasks consisted of two difficulty levels; one for younger children (7-9 years) and one for older children (10-12 years) to achieve maximum individual adaptation and training involvement. The training procedure was the same for all participants, with a standardized order of instructional rounds and training tasks. The first two training sessions were used to introduce the child to the five memory strategies. During the third and fourth training sessions, the child was asked to choose between the five memory strategies to allow for autonomous strategy use and to stimulate meta-memory processes. A neuropsychological re-assessment was performed immediately after termination of the four-week memory strategy training $(n=23)$, and at a follow-up assessment six months later $(n=22)$.

Children randomly allocated to the working memory training group $(n=22)$ undertook a computerized working memory training program (BrainTwister; www.braintwister.unibe.ch). This type of working memory training has previously been shown to improve working memory and fluid intelligence in adults $[27,28]$, and reading performance in children [18]. The training was introduced to the children and their parents at the University Hospital in a 30-minute one-to-one setting, where installation and implementation of the training was explained and practiced. Over four weeks, two verbal and one visual working memory task were trained adaptively (mean 19.4 sessions) according to a training plan. The training plan allowed for a mingled task order. Each training task lasted four minutes, resulting in a total training time of 12 minutes. A neuropsychological reassessment was performed immediately after termination of the four-week working memory training program $(n=22)$, and at a follow-up assessment six months later $(n=20)$.

Children randomly allocated to the control group $(n=23)$ underwent a neuropsychological assessment at TP1, then a passive waiting period of four weeks (no intervention). A neuropsychological re-assessment took place immediately after the waiting period (TP2, $n=23$ ), and again at six-month follow-up (TP3, $n=15$ ). After termination of the study protocol, children in the control group were free to choose between one of the two memory training approaches, or to have no further training.

\section{Assessment procedure}

Pre and post-test measures: At each time point, cognitive measures (Table 1) were assessed in the same order. If available, parallel versions of the neuropsychological tests were used at TP2 and TP3. Over all tests, raw scores were used for analyses of training effect. To examine the performance change between TP1 and TP2 (short-term effect) and TP1 and TP3 (long-term effect), we calculated a shortterm gain score and a long-term gain score. The short-term gain score refers to the difference between performance at TP1 and TP2: ((TP2-TP1)/TP1). The long-term gain score is defined in the same way: ((TP3-TP1)/TP3). The higher the gain score, the stronger the changes between the two time points.

Motivation and number of homework sessions: In both training groups, the child's motivation was assessed before the second, third and fourth week of training. This was done using a self-generated motivation questionnaire consisting of four items (e.g. "Did you have fun doing the training?" $0=$ not at all to 5=very much), resulting in a possible total motivation score of 20. Furthermore, the sum of all homework sessions was counted using the child's training diary, in which the date and time of day of each training session was listed.

Socioeconomic status: Socioeconomic status was defined as the highest level of maternal education as assessed via a questionnaire ( $1=$ no graduation; $2=$ college; $3=$ college of higher order education; $4=$ university degree). 
Table 1. Neuropsychological measures used to assess the training effect

\begin{tabular}{|c|c|c|}
\hline & Test & Measures/subtests used \\
\hline \multirow[t]{2}{*}{ Episodic memory $\Delta$} & $\begin{array}{l}\text { Verbal Learning and Memory Test (VLMT) } \\
{[39]}\end{array}$ & $\begin{array}{l}\text { Word list: Verbal learning } \\
\qquad \begin{array}{r}\text { Verbal recall } \\
\text { Verbal recognition }\end{array}\end{array}$ \\
\hline & $\begin{array}{l}\text { BASIC Memory and Learning Test MLT (Battery for } \\
\text { Assessment in Children) [7] }\end{array}$ & $\begin{array}{l}\text { Patterns: Visual learning } \\
\text { Visual recall } \\
\text { Visual recognition }\end{array}$ \\
\hline \multirow[t]{2}{*}{ Working memory $\square$} & WISC-IV [40] & Letter-number sequencing \\
\hline & $\begin{array}{l}\text { BASIC Memory and Learning Test MLT (Battery for } \\
\text { Assessment in Children) [7] }\end{array}$ & Spatial positioning \\
\hline \multirow[t]{2}{*}{ Short-term memory span $\Delta \square$} & WISC-IV [40] & Digit span forward \\
\hline & Corsi Block-Tapping Test [41] & Block tapping forward \\
\hline Fluid intelligence & WISC-IV [40] & Matrices \\
\hline Inhibition & $\begin{array}{l}\text { Test Battery of Attention Performance } \\
\text { (TAP) [42] }\end{array}$ & Selective attention (Go/NoGo) \\
\hline Cognitive flexibility & $\begin{array}{l}\text { Delis-Kaplan Executive Function System } \\
\text { (D-KEFS) [43] }\end{array}$ & $\begin{array}{l}\text { Color-Word Interference Test } \\
\text { (number of mistakes) }\end{array}$ \\
\hline Processing speed & WISC-IV [40] & Symbol search \\
\hline Reading & ELFE [44] & Sentence reading \\
\hline Arithmetic & WISC-IV [40] & Arithmetic \\
\hline Everyday memory & $\begin{array}{l}\text { Kognitive Probleme bei Kindern und Jugendlichen } \\
\text { (KOPKIJ) [45] }\end{array}$ & Memory scale \\
\hline
\end{tabular}

$\Delta$ This function is trained during memory strategy training

$\square$ This function is trained during working memory training

\section{Statistical analysis}

Data were analyzed with the Statistical Package for Social Sciences software for Windows, version 20 (SPSS, Chicago, Illinois). Because most of the variables were not normally distributed, nonparametric tests were calculated. Based on the directional hypothesis, tests were computed one-sided and a significance level of $\mathrm{p}<0.05$ was assumed. For multiple comparisons the Bonferroni method was used. Comparability of training groups with regards to cognitive performance at TP1 and demographical variables were calculated using the Chi-square or Wilcoxon rank-sum test. To determine the training effect, Wilcoxon rank-sum tests were calculated. For the short-term training effect, short-term gain scores for the control group were compared to the short-term gain scores for the memory strategy training group and the working memory training group, respectively. Long-term training effects were computed in the same way, using long-term gain scores. To calculate the relationship between gain scores and age, IQ, motivation, and number of homework sessions, Spearman correlations were applied (for this correlation we used an absolute gain score, TP2-TP1, TP3-TP1 respectively).

\section{Results}

The control and training groups were comparable with regards to demographic variables at TP1 (see Table 2). Cognitive performance did not differ significantly between the three groups at TP1.

In the memory strategy training group, children completed an average of 13.3 homework sessions ( $\mathrm{SD}=2.6$; range 8-16). Mean motivation across all four memory strategy training sessions was 15.9 $(\mathrm{SD}=2.4$; highest possible motivation score $=20)$. 
Table 2. Demographic data for the control and training groups

2a. Demographic data for the control and memory strategy training groups

\begin{tabular}{|c|c|c|c|c|c|}
\hline & Controls & $\begin{array}{c}\text { Memory strategy training } \\
\text { group }\end{array}$ & Total & $X^{2} / Z$ & $p$ \\
\hline & $n=23$ & $n=23$ & $n=46$ & & \\
\hline Sex (female) & 13 & 10 & 23 & 0.78 & 0.38 \\
\hline Age, years & $9.34(1.8)$ & $9.88(1.6)$ & 9.6 & -0.98 & 0.33 \\
\hline Gestational age, weeks & $29.5(2.4)$ & $29.7(2.1)$ & 29.6 & -0.13 & 0.89 \\
\hline Birth weight, g & $1243.0(389.9)$ & $1323.3(394.7)$ & 1283.2 & -0.86 & 0.39 \\
\hline IQ & $98.74(11.8)$ & $103.30(8.1)$ & 101.02 & -1.39 & 0.17 \\
\hline SES & $2.70(0.9)$ & $2.78(0.9)$ & 2.74 & -0.39 & 0.70 \\
\hline
\end{tabular}

2b. Demographic data of the control and working memory training groups

\begin{tabular}{|c|c|c|c|c|c|}
\hline & Controls & $\begin{array}{l}\text { Working memory training } \\
\text { group }\end{array}$ & Total & $X^{2} / Z$ & $p$ \\
\hline & $n=23$ & $n=22$ & $n=45$ & & \\
\hline Sex (female) & 13 & 10 & 23 & 0.55 & 0.46 \\
\hline Age, years & $9.34(1.8)$ & $9.45(1.8)$ & 9.4 & -0.18 & 0.86 \\
\hline Gestational age, weeks & $29.5(2.4)$ & $29.2(2.1)$ & 29.4 & -0.75 & 0.46 \\
\hline Birth weight, $g$ & $1243.0(389.9)$ & $1298.3(324.7)$ & 1270.0 & -0.69 & 0.49 \\
\hline IQ & $98.74(11.8)$ & $100.14(9.8)$ & 99.4 & -0.55 & 0.59 \\
\hline SES & $2.70(0.9)$ & $2.68(1.0)$ & 2.69 & -0.09 & 0.93 \\
\hline
\end{tabular}

Note: Data are mean $(\mathrm{SD})$; $\mathrm{SES}=$ socioeconomic status

On average, children in the working memory training group completed 20 training sessions $(\mathrm{SD}=2.4$; range 15-25). Mean total motivation was $14.6(\mathrm{SD}=4.3)$.

\section{Memory strategy training}

Following memory strategy training, children showed significantly stronger improvement of trained functions (verbal/visual learning, visual recall and short-term memory; see Table 3) than the control group. Non-trained functions improved significantly more strongly in the training groups compared to the control group over the short-term (working memory: letter-number sequencing, spatial positioning, mental arithmetic). At the six-month follow-up assessment, improvement of verbal learning and working memory (letter-number sequencing), and parents' rating of their child's everyday memory functions remained significantly stronger in the memory strategy training group compared to the control group.

In the memory strategy training group, a negative correlation was detected between age at TP1 and the arithmetic gain score $(r=-.51, p=0.017)$, with a higher gain score seen in younger children. Intelligence was positively correlated with the visual recall gain score (visual recall: $r=0.68, p=0.007$ ), and negatively correlated with the verbal working memory gain score (letter-number-sequencing $r=-0.432, p=0.039$ ). Motivation was positively correlated with the visual short-term memory gain score (spatial positioning $r=0.46, p=0.026)$. Performance at TP1 related negatively to the strength of the gain score in various cognitive domains (see Table 4), indicating higher gain scores in children with low cognitive performance before the training. This relationship was even apparent when controlling for age at TP1. 
Table 3. Short- and long-term training effects

\begin{tabular}{|c|c|c|c|c|}
\hline \multirow[b]{3}{*}{ Neuropsychological measures } & \multicolumn{2}{|c|}{ Memory strategy training vs. controls } & \multicolumn{2}{|c|}{ Working memory training vs. controls } \\
\hline & Short-term effect & Long-term effect & Short-term effect & Long-term effect \\
\hline & $Z$ & $Z$ & $Z$ & $Z$ \\
\hline \multicolumn{5}{|l|}{ Episodic memory } \\
\hline Verbal learning & $-3.45 * * *+$ & $-2.75 * *+$ & -0.65 & -0.10 \\
\hline Verbal recall & -0.94 & -0.20 & -0.57 & -0.01 \\
\hline Verbal recognition & -1.02 & -0.21 & -1.27 & -0.05 \\
\hline Visual learning & $-3.06 * *+$ & -1.30 & -0.21 & -1.53 \\
\hline Visual recall & $-1.98^{*}$ & -0.58 & -1.49 & -0.27 \\
\hline Visual recognition & -1.01 & -1.21 & -1.45 & -1.45 \\
\hline \multicolumn{5}{|l|}{ Working memory } \\
\hline Letter-number sequencing & $-3.40 * * *+$ & $-3.52 * * *+$ & $-2.09 *$ & $-2.10^{*}$ \\
\hline Spatial positioning & $-1.74 *$ & -1.53 & -0.52 & -0.65 \\
\hline \multicolumn{5}{|l|}{ Short-term memory span } \\
\hline Digit span forward & -0.64 & -0.14 & -1.04 & -0.17 \\
\hline Block tapping forward & $-2.18^{*}$ & -0.85 & $-2.06^{*}$ & -0.65 \\
\hline Fluid intelligence matrices & -0.20 & -0.99 & -0.46 & -1.52 \\
\hline Inhibition selective attention & -1.62 & -1.10 & -0.05 & -0.69 \\
\hline \multicolumn{5}{|l|}{ Cognitive flexibility } \\
\hline Colour-word interference & -0.40 & -0.65 & -0.76 & -0.32 \\
\hline \multicolumn{5}{|l|}{ Processing speed } \\
\hline Symbol search & -0.96 & -0.65 & -1.61 & -1.08 \\
\hline \multicolumn{5}{|l|}{ Reading } \\
\hline Sentence reading & -1.05 & -0.02 & -0.65 & -0.39 \\
\hline Arithmetic & $-2.32 * *$ & -0.01 & -1.01 & -0.67 \\
\hline Everyday memory & -0.45 & $-2.70 * *$ & -0.22 & $-1.91 *$ \\
\hline
\end{tabular}

\section{Working memory training}

Following working memory training, there was a significantly stronger improvement in trained functions (working memory, short-term memory; see Table 3) when compared to the control group. There were no significant group differences in the improvement of non-trained functions. At the sixmonth follow-up assessment, improvement of trained verbal working memory remained significantly stronger, and parents' rating of their child's everyday memory functions was significantly better in the training group compared to the control group.

In the working memory training group, age at TP1 was negatively correlated with processing speed gain score (symbol search: $r=-0.44, p=0.044$ ), indicating higher gain scores in younger children. Intelligence was positively correlated with the visual learning gain score (visual learning: $r=0.64, \quad p=0.002$ ), and negatively correlated with the arithmetic gain score $(r=-0.48, \quad p=0.032)$. Motivation was positively associated with visual short-term memory (short-term gain score; block tapping forward $r=0.46, p=0.031$ ). Performance at TP1 was negatively correlated with various short and long-term gain scores (see Table 4), with higher gain scores in children with low cognitive performance, even when controlling for age at TP1.

In both training groups, neither the number of training or homework sessions, nor socioeconomic status was associated with short and long-term gain scores. 
Table 4. Correlations between short-term gain score and performance before training (TP1)

\begin{tabular}{|c|c|c|c|}
\hline & Memory strategy training & Working memory training & Control group \\
\hline Measures & Short-term GS x TP1 & Short-term GS x TP1 & Short-term GS x TP1 \\
\hline Word list: Verbal learning & -0.33 & $-0.44 *$ & -0.17 \\
\hline Verbal recall & $-0.80 * * *+$ & $-0.55 * *$ & $-0.81 * * *+$ \\
\hline Verbal recognition & $-0.61 * *+$ & $-0.49 *$ & -0.20 \\
\hline Patterns: Visual learning & -0.39 & -0.09 & -0.37 \\
\hline Visual recall & $-0.80 * * *+$ & $-0.63 * * t$ & $-0.55 * *$ \\
\hline Visual recognition & -0.33 & -0.15 & -0.26 \\
\hline Letter-number sequencing & $-0.74 * * *+$ & -0.07 & -0.32 \\
\hline Spatial positioning & $-0.51 *$ & -0.14 & $-0.47 *$ \\
\hline Digit span forward & -0.01 & $-0.58 * *$ & $-0.67 * *+$ \\
\hline Block tapping forward & $-0.44 *$ & -0.28 & $-0.50 * *$ \\
\hline Matrices & -0.33 & -0.01 & $-0.47 *$ \\
\hline Selective attention (Go/NoGo) & $-0.69 * * *+$ & $-0.62 * *+$ & $-0.57 * *$ \\
\hline $\begin{array}{l}\text { Colour-word interference test } \\
\text { (number of mistakes) }\end{array}$ & $-0.65 * * *+$ & $-0.72 * *+$ & -0.40 \\
\hline Symbol search & 0.15 & -0.36 & -0.18 \\
\hline Sentence reading & -0.14 & -0.37 & $-0.54 *$ \\
\hline Arithmetic & $-0.62 * *+$ & -0.33 & -0.03 \\
\hline
\end{tabular}

Note: $p$ one-sided, ${ }^{*} p<.05,{ }^{* *} p<.01,{ }^{* * *} p<.001, \$$ remains significant after Bonferroni correction

\section{Discussion}

Following two different memory training approaches, children who were born very preterm showed improvements in memory functions over both the short and long term, independent of the type of training.

In more detail, children who undertook a course of memory strategy training sessions exhibited a near and far transfer effect, with immediate improvement of trained aspects of memory (verbal and visual learning and recall, visual short-term memory), and improvement of non-trained cognitive domains (working memory, mental arithmetic). At the sixmonth follow-up assessment, improvements in trained functions (verbal learning) and non-trained domains were still present (verbal working memory, parental rating of everyday memory performance), whereas no performance changes occurred in the control group, neither at short nor at long term

Children following a program of working memory training presented a significant improvement in trained functions (verbal working memory, visual short-term memory). Non-trained functions did not improve after the training. At the six-month followup assessment, improvement of verbal working memory remained significant, and parents' rating of their child's everyday memory functions was better in the working memory training group compared to the control group.

To summarize, these results show an immediate effect of memory training on cognitive domains that are structurally related to trained functions (near transfer). Following memory strategy training, there was even an improvement of structurally unrelated tasks such as mental arithmetic (far transfer). Longterm training effects occurred in different memory domains after both types of training.

\section{Transfer effect}

Why did a far transfer effect to structurally different cognitive domains only occur after memory strategy training? We assume that participants generalize the skills learned during memory strategy training to other cognitive domains, especially where multiple 
memory strategies were used [5, 7]. In memory strategy training studies applying only one memory strategy, no transfer effect to non-trained cognitive domains occurred [8]. Where multiple memory strategies were used, a far transfer effect is more likely to occur $[7,11]$. Support for this assumption is given when considering meta-memory; knowledge and consciousness about one's own memory processes. Memory strategy training requires children to recall different memory strategies, and then to autonomously apply the most applicable strategy to the situation at hand. Hence, our memory strategy training strains meta-memory to a high extent. Metamemory is known to be a precondition for learning and applying memory strategies [29]. Pre-school children have only basic meta-memory skills, whereas at the age of around 12 years, meta-memory is suggested to be fully developed and considered a good predictor for memory performance [23]. We therefore suggest that the effect of memory strategy training coincides with an improvement of metamemory.

\section{Low performers are high gainers}

It is of great clinical relevance to determine factors that influence the training effect. Our analysis showed that, in particular, children who had low cognitive performance before the training program improved their performance through memory training. In other words, our study revealed that low performers are high gainers, independent of the memory training approach. The influence of performance level on the training effect has been shown in previous studies using working memory training activities [16, 30]. For memory strategy training, we assume that low performers benefit more because they have not yet spontaneously applied memory strategies to solve a task, whereas high-performers might have already referred to memory strategies, thus enabling high cognitive performance levels.

\section{Plasticity of the child's brain}

Children tend to show greater neural and behavioral plasticity than adults [31], and hence training-induced plasticity is expected to be enhanced in the developing brain. A study by Brehmer et al. (2007), compared training-induced plasticity across the lifespan [10]. The authors taught healthy young (9-12 years), middle-aged (20-25 years), and older participants (65-78 years) a modified version of the 'method of loci, a memory strategy applied to encode and retrieve words through location cues. In line with current views from lifespan psychology [24], children profited more from memory strategies than older adults [10]. Also after working memory training, Brehmer et al. (2012) showed that training and transfer gains were somewhat greater for younger than for older adults in some tasks, but comparable across age groups in other tasks [32]. Our data support the notion of high functional plasticity in children: a four-week training course led to an improvement in different aspects of cognition in children who were born very preterm. A subgroup of the present study population underwent functional magnetic resonance imaging to detect the cerebral visual working memory network before and after the training or waiting period. Interestingly, results show a significant decrease of neural activity within the fronto-parietal working memory network in both memory training groups whereas no neural changes occurred in the control group [33]. These pilot data point towards a training-related decrease of brain activation, independent of the training approach and clearly highlight the high training-induced plasticity of the child's brain during development. In a future study, it would be interesting to compare the effect size of memory training approaches, and the magnitude of the transfer effect across lifespan.

In previous studies we have shown that our very preterm study population presents a maturational spurt at around the age of 7-12 years, which does not occur in the healthy term-born control sample. On a cognitive [34] but also on a neural [35] and functional network level [36,37] group differences were significantly more pronounced between our preterm and control samples at a younger (7-8 and 9-10 years) age than at an older (11-12 years) age. The observation of a maturational catch-up at early school-age in very preterm-born children might be associated with high training-induced plasticity after our rather short memory training programs. Whether the training effect would be similar in term-born control children, where maturational changes are less salient at early school-age, remains to be determined. 


\section{Limitations}

Studies of memory training are not as rigorous as standardized clinical trials. Although individual measures such as motivation or number of homework sessions were assessed, there always remains some inter-individual variance. The training and homework sessions implied enhanced attention and care from parents and trainers, which might influence the child's cognitive performance level indirectly (e.g. through increased self-confidence or strengthening of the child-caregiver relationship), and hence favor the training groups as opposed to the control group. This variance must be considered when interpreting results of memory training studies. The present study only included very preterm-born children with an IQ $>85$ and few-to-no neonatal complications. Hence, data cannot be generalized to any preterm sample. Furthermore, the optimal duration and spacing of memory training sessions, and the role of reward have yet to be determined. Memory training might be more useful in association with ecological tasks [38], or ongoing low-level training over the months and years.

\section{Conclusions}

Memory training is an effective way to improve different aspects of memory at early school-age, but particularly in the case of memory strategy training also helps to improve non-trained cognitive domains in children who were born very preterm. However, the child's cognitive performance level before undertaking training significantly influences the training's success, with low performers being high gainers, independent of the training approach. Consequently, these data emphasize the need to educate parents, teachers and therapists on how to introduce memory training activities to children who were born very preterm, but also to children with various kinds of learning difficulties in order to decrease the risk of academic problems.

\section{Acknowledgements}

We thank the Swiss National Neonatal Follow Up Group for their collaboration, and Ines MürnerLavanchy, Tanja Kohlen, Stéphanie Herzog, Tina Schneider and Susanne Röthlisberger for their help.

\section{References}

1. Anderson P, Doyle LW. Neurobehavioral outcomes of school-age children born extremely low birth weight or very preterm in the 1990s. JAMA. 2003;289:3264-72.

2. Aarnoudse-Moens CS, Weisglas-Kuperus N, van Goudoever JB, Oosterlaan J. Meta-analysis of neurobehavioral outcomes in very preterm and/or very low birth weight children. Pediatrics. 2009;124:717-28.

3. Morrison AB, Chein JM. Does working memory training work? The promise and challenges of enhancing cognition by training working memory. Psychon Bull Rev. 2011;18:46-60.

4. Klingberg T, Fernell E, Olesen PJ, Johnson M, Gustafsson P, Dahlström K, et al. Computerized training of working memory in children with ADHD--a randomized, controlled trial. J Am Acad Child Adolesc Psychiatry. 2005;44:177-86.

5. Turley-Ames K, Whitfield M. Strategy training and working memory task performance. J Mem Lang. 2003;49:446-68.

6. McNamara DS, Scott JL. Working memory capacity and strategy use. Mem Cogn. 2001;29:10-7.

7. Lepach A, Petermann F. Battery for Assessment in Children: Merk- und Lernfähigkeitstest für 6- bis 16jährige (BASIC-MLT). Bern: Huber; 2008.

8. Conners FA, Rosenquist CJ, Arnett L, Moore MS, Hume LE. Improving memory span in children with Down syndrome. J Intellect Disabil Res. 2008;52:244-55.

9. Spahn V, Kulke H, Kunz M, Thöne-Otto A, Schupp W, Lautenbacher S. Is the neuropsychological treatment of memory specific or unspecific? Zeitschrift für Neuropsychol. 2010;21:239-45.

10. Brehmer $\mathrm{Y}$, Li SC, Muller $\mathrm{V}$, von Oertzen $\mathrm{T}$, Lindenberger U. Memory plasticity across the life span: uncovering children's latent potential. Dev Psychol. 2007;43:465-78.

11. Yerys BE, White DA, Salorio CF, McKinstry R, Moinuddin A, DeBaun M. Memory strategy training in children with cerebral infarcts related to sickle cell disease. J Pediatr Hematol Oncol. 2003;25:495-8.

12. Leather CV, Henry LA. Working memory span and phonological awareness tasks as predictors of early reading ability. J Exp Child Psychol. 1994;58:88-111.

13. Adams JW, Hitch GJ. Working memory and children's mental addition. J Exp Child Psychol.. 1997;67:21-38.

14. Miyake A, Friedman NP, Emerson MJ, Witzki AH, Howerter A, Wager TD. The unity and diversity of executive functions and their contributions to complex "Frontal Lobe" tasks: a latent variable analysis. Cogn Psychol. 2000;41:49-100.

15. Conway ARA, Kane MJ, Engle RW. Working memory capacity and its relation to general intelligence. Trends Cogn Sci. 2003;7:547-52. 
16. Jaeggi SM, Buschkuehl M, Jonides J, Shah P. Short- and long-term benefits of cognitive training. Proc Natl Acad Sci USA. 2011;108:10081-6.

17. Karbach J, Strobach T, Schubert T. Adaptive workingmemory training benefits reading, but not mathematics in middle childhood. Child Neuropsychol. 2015;21:285:301.

18. Loosli S V, Buschkuehl M, Perrig WJ, Jaeggi SM. Working memory training improves reading processes in typically developing children. Child Neuropsychol. 2012;18:62-78.

19. Holmes J, Gathercole SE, Dunning DL. Adaptive training leads to sustained enhancement of poor working memory in children. Dev Sci. 2009;12:F9-15.

20. Thorell LB, Lindqvist S, Bergman Nutley S, Bohlin G, Klingberg T. Training and transfer effects of executive functions in preschool children. Dev Sci. 2009;12:10613.

21. Klingberg $\mathrm{T}$, Forssberg $\mathrm{H}$, Westerberg $\mathrm{H}$. Training of working memory in children with ADHD. J Clin Exp Neuropsychol. 2002;24:781-91.

22. Dunning DL, Holmes J, Gathercole SE. Does working memory training lead to generalized improvements in children with low working memory? A randomized controlled trial. Dev Sci. 2013;16:915-25.

23. Schneider W, Pressley M. Memory development between 2 and 20. 2nd ed. New York: Springer; 1997. p. 89-120.

24. Baltes PB. Theoretical propositions of life-span developmental psychology: On the dynamics between growth and decline. Dev Psychol. 1987;23:611-26.

25. Johnson S, Hennessy E, Smith R, Trikic R, Wolke D, Marlow N. Academic attainment and special educational needs in extremely preterm children at 11 years of age: the EPICure study. Arch Dis Child Fetal Neonatal Ed. 2009;94:283-9.

26. Everts R, Ritter BC. Memo, der vergessliche Elefant. Mit Gedächtnistraining spielerisch zum Lernerfolg. Bern: Huber; 2013.

27. Jaeggi SM, Buschkuehl M, Jonides J, Perrig WJ. Improving fluid intelligence with training on working memory. Proc Natl Acad Sci USA. 2008;105:6829-33.

28. Buschkuehl M, Jaeggi SM, Hutchison S, Perrig-Chiello P, Däpp C, Müller M, et al. Impact of working memory training on memory performance in old-old adults. Psychol Aging. 2008;23:743-53.

29. Pressley M, Borkowski JG, O’Sullivan JT. Memory strategy instruction is made of this: Metamemory and durable strategy use. Educ Psychol. 1984;19:94-107.

30. Rudebeck SR, Bor D, Ormond A, O'Reilly JX, Lee $\mathrm{ACH}$. A potential spatial working memory training task to improve both episodic memory and fluid intelligence. PLoS One. 2012;7:e50431.

31. Gogtay N, Giedd JN, Lusk L, Hayashi KM, Greenstein $\mathrm{D}$, Vaituzis AC, et al. Dynamic mapping of human cortical development during childhood through early adulthood. Proc Natl Acad Sci USA. 2004;101:8174-9.

32. Brehmer $\mathrm{Y}$, Westerberg $\mathrm{H}$, Bäckman L. Workingmemory training in younger and older adults: training gains, transfer, and maintenance. Front Hum Neurosci. 2012;6:1-6.

33. Everts R, Mürner-Lavanchy I, Schroth G, Steinlin M. Neural change following different memory training approaches in very preterm born children - A pilot study. Dev Neurorehabil. 2015:1-11.

34. Ritter BC, Nelle M, Perrig W, Steinlin M, Everts R. Executive functions of children born very preterm deficit or delay? Eur J Pediatr. 2013;172:473-83.

35. Mürner-Lavanchy I, Steinlin M, Nelle M, Rummel C, Perrig WJ, Schroth G, et al. Delay of cortical thinning in very preterm born children. Early Hum Dev. 2014;90:443-50.

36. Mürner-Lavanchy I, Steinlin M, Kiefer C, Weisstanner C, Ritter BC, Perrig W, Everts R. Delayed development of neural language organization in very preterm born children. Dev Neuropsychol. 2014;39:529-42.

37. Mürner-Lavanchy I, Ritter BC, Spencer-Smith MM, Perrig WJ, Schroth G, Steinlin M, et al. Visuospatial working memory in very preterm and term born children - impact of age and performance. Dev Cogn Neurosci. 2014;9:106-16.

38. Cavallini E, Pagnin A, Vecchi T. Aging and everyday memory: the beneficial effect of memory training. Arch Gerontol Geriatr. 2003;37:241257.

39. Helmstaedter C, Lendt M, Lux S. Verbaler Lern- und Merkfähigkeitstest (VLMT). Weinheim: Beltz; 2001.

40. Petermann F, Petermann U. Hamburg-WechslerIntelligenztest für Kinder - IV (HAWIK IV). 2nd ed. Bern: Hans Huber-Verlag; 2008.

41. Pagulayan KF, Busch RM, Medina KL, Bartok JA, Krikorian R. Developmental normative data for the Corsi Block-tapping task. J Clin Exp Neuropsychol. 2006;28:1043-52.

42. Zimmermann P, Fimm B. Testbatterie zur Aufmerksamkeitsprüfung (TAP). Herzogenrath: Psytest; 2002.

43. Delis D, Kaplan E, Kramer J. Delis-Kaplan Executive Function System (DKEFS). San Antonio, TX: The Psychological Corporation; 2001.

44. Lenhard W, Schneider W. ELFE 1-6: Ein Leseverständnistest für Erst- bis Sechstklässler. Göttingen: Hogrefe; 2006.

45. Gleissner U, Lendt M, Mayer S, Elger CE, Helmstaedter C. Kognitive Probleme bei Kindern und Jugendlichen, Vorstellung eines Fragebogens - A new questionnaire for recognizing cognitive problems in children and adolescents. Nervenarzt 2006;77:449-65. 